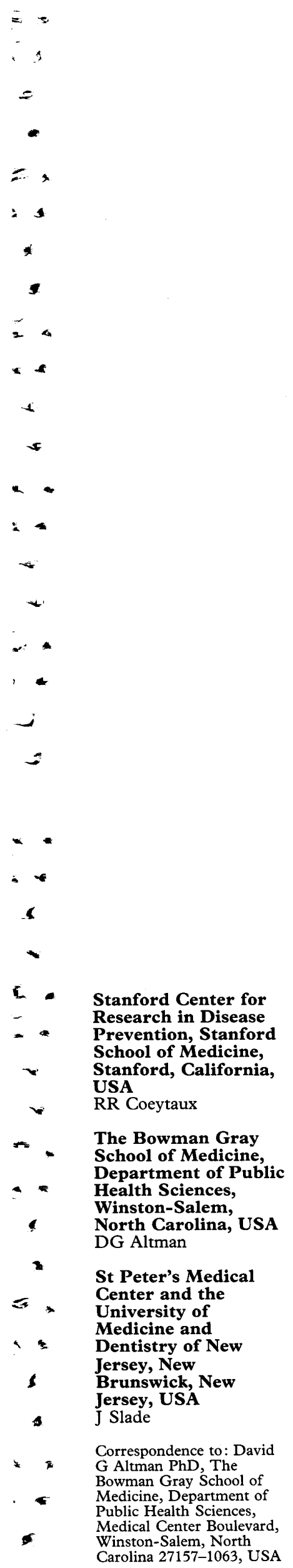

\title{
Tobacco promotions in the hands of youth
}

\author{
Remy R Coeytaux, David G Altman, John Slade
}

\begin{abstract}
Objective-To examine the extent to which minors in the United States are exposed to and participate in tobacco promotion campaigns.

Design-1047 minors (12-17 years old) and 290 young adults (18-24 years old) were interviewed in July and August 1993 as part of a national, random digit dial telephone survey designed to investigate the participation by young people in tobacco promotion campaigns.

Results - 366 minors surveyed had participated in tobacco promotion campaigns $(35 \%)$. Among this group, 111 (10.6\% of total respondents) reported having owned at least one tobacco promotional item. The mean number of items owned by these 111 respondents was 3.2. By applying these figures to the US population in this age group, an estimated 7.4 million minors have participated in tobacco promotion campaigns, and 2.2 million of these have collectively. owned an estimated seven million tobacco promotional items.

Conclusions-Despite claims by the tobacco industry that promotional items are intended solely for smokers at least 21 years of age, millions of young people, both smokers and non-smokers, possess and use such items. This popular form of advertising lacks warning labels and familiarises minors with tobacco products.
\end{abstract}

(Tobacco Control 1995; 4: 253-257)

Keywords: tobacco; advertising and promotion; youth; minors

\section{Introduction}

The practice of enticing consumers to purchase a particular brand of tobacco by offering promotional items dates back to the late nineteenth century, when collectible cards were included in cigarette packs. ${ }^{1}$ Today, this marketing strategy has grown to include a wide array of items bearing the logo of the particular tobacco product being promoted.

In this report we use the term "promotion campaign" to refer to the practice of offering promotional items such as clothing or equipment, either concurrent with the purchase of tobacco products, or in exchange for proofs of purchase or coupons obtained through the purchase of tobacco products. Tobacco pro- motional items range from relatively small items such as lighters, caps, $T$ shirts, or coffee mugs given at the time of purchase of tobacco products to expensive leather jackets or backpacking gear obtainable (along with less extravagant items) through coupon redemption or direct purchase. Examples of such tobacco promotions include Camel Cash coupons, which are colourful imitations of US currency attached to cigarette packs, and Marlboro Miles obtainable with the purchase of Marlboro cigarettes, which can be collected and redeemed for promotional items. Many of these items are appealing to young people, and the practice of distributing them for the promotion of tobacco products has been implicated in the recent rise in sales to minors of certain brands of cigarettes. ${ }^{2,3}$

Tobacco manufacturers are increasingly relying on promotional items to entice US consumers to purchase their tobacco products. Domestic cigarette advertising and promotional expenditures have increased from $\$ 3.99$ billion in 1990 to $\$ 5.23$ billion in 1992 , to $\$ 6.03$ billion in $1993 ., 5$ Spending on the distribution of specialty items, which consist primarily of tobacco promotional items, has increased from $\$ 307$ million to $\$ 400$ million to $\$ 756$ million in that same time period, ${ }^{4,5}$ while expenditures for coupons and retail valueadded promotions, which include non-cigarette items such as key chains or lighters given away at the time of purchase of cigarettes, more than doubled between 1990 and 1993, from $\$ 1.2$ billion to $\$ 2.6$ billion. ${ }^{4,5}$

The magnitude of these expenditures, as well as the dramatic increases in recent years, raises concerns about the extent to which young people are being exposed to and influenced by tobacco promotions. Tobacco manufacturers have attempted to counter criticism that promotional items reach young people by instituting a policy whereby mail orders for tobacco promotional items must be accompanied by the customer's signature attesting to the fact that he or she is a smoker 21 years of age or older. Age and smoking status are not verified in any way, however, and promotional items and samples of tobacco products have been delivered regardless of true age or smoking behaviour.

We conducted a national, random digit dial telephone survey of residents of the United States between the ages of 12 and 24 years to examine the extent to which young people are exposed to and participate in tobacco promotion campaigns. Our data provide estimates for the number of youth who have acquired 
tobacco promotional items as well as how minors have obtained these items.

\section{Methods}

\section{DESIGN AND PROCEDURE}

Data in this study were collected from telephone interviews of a random sample of eligible households in the United States. A questionnaire was developed and administered by telephone by interviewers at Freeman, Sullivan and Company, a social science research firm in San Francisco, California. Twenty three interviewers were trained to administer the study questionnaire in English; two were trained to administer it in Spanish. Survey responses were entered directly into a computer, using a computer assisted telephone interview (CATI) system. On average, the questionnaire took approximately 12 minutes to administer.

Informed consent was sought from each respondent as well as from their parents or guardians when the respondent was under the age of 18. The interviewer would first explain the study to the parent of an eligible minor and seek informed consent. If the parent declined consent, the accrual attempt was considered to be a refusal and no further calls were made to that household. If the parent provided informed consent, the interviewer would ask to speak to the selected respondent and would call back if the respondent was unavailable at that time. Respondents were told that they were selected randomly, their responses were confidential and anonymous, they would not be called again for this study, and they would not receive remuneration for their participation. To limit response bias, parents were asked to allow the child to respond to the questions in private. Parents who refused to provide such privacy were counted as refusals in response rate calculations.

\section{SAMPLE AND SUBJECT ACCRUAL}

The study sample consists of 1047 residents of the United States between the ages of 12 and 17 years inclusive, and 290 US residents between the ages of 18 and 24 years. Respondents were selected randomly to partake in a telephone survey of participation in tobacco promotion campaigns. A list of telephone numbers was generated by and purchased from Survey Sampling Inc in Fairfield, Connecticut. All area codes in the United States were eligible for the sampling frame, and prefixes thought to be non-residential were excluded. Persons answering the telephone confirmed household eligibility criteria and the number of eligible persons. One eligible subject per household was selected randomly by computer to be interviewed. The interviewer would call back at another time if the eligible respondent was not available. All respondents were given a toll-free number to call if they preferred being interviewed at another time or place. This option was provided to facilitate minors' privacy.

During the first stage of the study, all
English or Spanish speaking subjects between the ages of 12 and 24 years inclusive were eligible. Once a predetermined sample size of 290 respondents between the ages of 18 and 24 was obtained, only minors between the ages of 12 and 17 were recruited. Subject accrual and telephone interviews were conducted in July and August, 1993. The sole exclusion criterion was inability to speak English or Spanish.

\section{RESPONSE RATES}

A total of 30147 calls was made. Of these, 2155 $(7.1 \%)$ reached households that were known to include at least one eligible respondent, and 3938 calls $(13.1 \%$ ) reached persons who hung up the telephone before household eligibility could be determined. Of the 2155 eligible households contacted, $1337(62.0 \%)$ resulted in a completed interview. Of these, 1047 were between the ages of 12 and 17 years. The remaining 290 interviews were conducted with young adults, aged 18-24 years. Eight hundred and eighteen of the households known to include an eligible respondent $(32.0 \%)$ declined to participate. Of these, 331 refusals came from parents and 487 directly from the respondents.

\section{DATA ANALYSIS}

Data analyses were performed using the Statistical Package for the Social Sciences (SPSS) software. Student's $t$ tests were used for analysing continuous data, and $\chi^{2}$ tests were used for categorical data.

\section{Results}

Completed interviews were obtained for 1047 minors between the ages of 12 and 17 years, inclusive, and 290 young adults aged 18 to 24 years. The sample of minors was comprised of $50 \%$ males and $78 \%$ Caucasians. With respect to tobacco use, $41 \%$ had used cigarettes or smokeless tobacco in their lifetime, $17 \%$ reported using tobacco in the previous month, and $46 \%$ lived in a household in which there was at least one tobacco user. Among the young adult respondents, $40 \%$ were male, $77 \%$ were white, $73 \%$ had used tobacco, $39 \%$ had used tobacco in the past month, and $38 \%$ lived in a household in which there was at least one tobacco user.

Respondents who reported either having owned a tobacco promotional item, or having collected coupons such as Camel Cash or Marlboro Miles, or having possessed a catalogue distributed by a tobacco manufacturer that depicted promotional items obtainable through coupon redemption, were considered to have participated in tobacco promotion campaigns. According to this definition, 366 $(35.0 \%)$ of minors surveyed had participated in such campaigns. Extrapolated to the total population of 21 million US residents between the ages of 12-17 years, ${ }^{6}$ this corresponds to an estimated 7.4 million American adolescents. Of these participants in tobacco promotion campaigns, $111(10.6 \%$ of all minors surveyed $)$ 


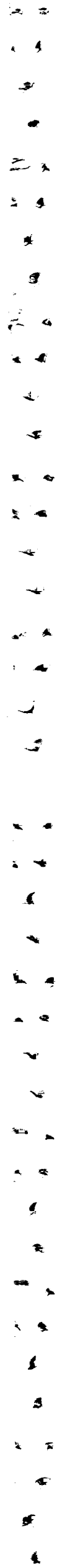

reported having owned at least one tobacco promotional item, corresponding to 2.2 million minors in the USA. The mean number of items owned by respondents who reported having owned a promotional item was 3.2. Thus an estimated 7.1 million tobacco promotional items have been in the hands of young people of between 12 and 17 years of age.

Exposure to tobacco promotions was even higher than participation rates: $83.5 \%$ of all minors surveyed were aware of at least one tobacco promotions campaign and 682 $(65.1 \%)$ had at least one friend or relative whom they knew to have owned a promotional item for tobacco products. Of these, 467 $(44.6 \%$ of minors surveyed) had a friend or relative under the age of 18 who owned a tobacco promotional item.

Participation in tobacco promotion campaigns was greater among the young adult respondents. Of the 290 respondents between the ages of 18 and 24 years, $147(50.7 \%)$ participated in tobacco promotion campaigns as defined above, and $87(30.0 \%)$ owned a promotional item. Of note, however, is the finding that awareness of tobacco promotions was the same among minors and young adults: 874 minors $(83.5 \%)$ and 243 young adults $(83.8 \%)$ surveyed had heard of at least one tobacco promotion campaign.

Of the 173 minors who reported having used tobacco in the past month, $42(24.3 \%)$ also owned at least one promotional item. This represents a more than threefold greater proportion than the $7.9 \%$ of respondents who were not active tobacco users who owned tobacco promotional items ( $\mathrm{p} \ll 0.001)$. Of the 111 respondents who reported ever having owned a tobacco promotional item, however, $42(37.8 \%)$ were active tobacco users and 69 $(62.2 \%)$ were not active users. This corresponds to an estimated 1.4 million young people under 18 years of age who obtained tobacco promotional items who were not current smokers, in addition to an estimated 800000 youth who smoke. These figures do not include children under the age of 12 and young adults between the ages of 18 and 20 years.

Owners of tobacco promotional items were identified as those respondents who answered "yes" to the following question: "Some tobacco companies provide promotional items to the public that you can buy or receive for free. Have you ever bought or received for free any product that promotes a tobacco brand or was distributed by a tobacco company?" The 111 minors who answered this question in the affirmative $(10.6 \%)$ were then asked the question, "How did you receive these promotional items?" The results are as follows: $54.1 \%$ obtained an item from a friend or relative; $12.6 \%$ by coupon redemption; $11.7 \%$ by unsolicited mail; $9.9 \%$ by buying the item directly; $7.2 \%$ with a cigarette purchase; $5.4 \%$ at an event or on the street; and $15.3 \%$ by other means or "don't know" (multiple responses were accepted, so the sum of the percentages is greater than $100 \%$ ). Thus at least $12.6 \%$ of the 7.1 million tobacco promotional items (corresponding to approximately 890000 items) estimated to have been owned by minors were obtained by the minors themselves redeeming coupons. An additional $7.2 \%$ of minors surveyed obtained at least one of their items with the purchase of a tobacco product, representing an additional 510000 items.

These estimates, however, do not account for the $54.1 \%$ of respondents who had been given a promotional item by a friend or relative that had originally come from a retailer or manufacturer. By assuming that these items were obtained according to the same distribution of responses reported above, and by calculating an adjusted distribution by eliminating the "friend or relative" category and weighting the remaining means accordingly, we estimate that at least $20.3 \%$ of the promotional items in the hands of minors were originally obtained through coupon redemption, with an additional $11.6 \%$ of items obtained directly through the purchase of a tobacco product. This represents an estimated 1.4 million items obtained through coupon redemption, and 820000 obtained with the purchase of a tobacco product. These estimates may still underestimate the importance of promotional items obtained in conjunction with the purchase of tobacco products because they do not take into account the $15.3 \%$ of "other" or "don't know" responses.

Two sources of promotional items reported above, coupon redemption and receipt of unsolicited items by mail, involve direct mailings to youth. In addition, 17 minors surveyed $(1.6 \%)$ reported having received a free sample of tobacco in the mail, and 47 $(4.5 \%)$ responded "yes" to the question, "Some brands of cigarettes, snuff or chewing tobacco send out mail such as a survey, coupons, free gifts, merchandise offers, catalogs or free tobacco products. Have you ever received such mail addressed to you personally ?" Eighty respondents $(7.6 \%)$ had received some form of direct mailing from a tobacco company. This corresponds to an estimated 1.6 million minors nationwide who have received mail from a tobacco manufacturer and whose names presumably remain on company mailing lists.

\section{Discussion}

Promotional items distributed by tobacco companies are reaching American youth, irrespective of age or tobacco use status. An estimated 7.4 million young people have either owned a promotional item, had a tobacco promotions catalogue in their possession, or collected coupons such as Camel Cash or Marlboro Miles. Approximately 2.2 million of these, $62 \%$ of whom denied having used tobacco in the past month, have collectively acquired an estimated 7.1 million tobacco promotional items.

Eleven percent of the young people in this study reported having owned promotional items. This compares with a $30 \%$ ownership 
among the same age group reported by a national survey conducted by the Gallup International Institute. ${ }^{7}$ The different findings from the two surveys may be related to differences in consent procedures (the Gallup Institute survey did not obtain parental consent), the wording of survey questions, or sample selection procedures. The high rates of youth participation in tobacco promotion campaigns reported in these two studies are consistent with our own regular interaction with young people in educational sessions. When tobacco promotional items are displayed to them during these sessions, many young people express a strong interest in obtaining those items.

Widespread youth exposure to, ownership of, and use of tobacco promotional items by young people raises numerous concerns. First, there may be a causal relationship between ownership or pursuit of promotional items and tobacco consumption. This may occur directly by encouraging children and adolescents to purchase tobacco products in order to acquire coupons that can be exchanged for desirable promotional items. Moreover, adolescents and preadolescents may be encouraged to consume tobacco in an environment in which items promoting tobacco products are common. By simply browsing through promotional catalogues or observing their friends use promotional items, young people become familiar with brand names, marketing themes, and tobacco products. This familiarity may help to create an atmosphere in which tobacco use is considered the norm rather than the exception.

In our survey, one half of the promotional items obtained by minors had been given to them by a friend or relative. While tobacco manufacturers may deny responsibility for transfers of tobacco or promotional products from adults to minors, many of the items nevertheless end up in the hands of minors. Moreover, the minors have obtained the items from credible and respected sources. This is likely to enhance and further reinforce the selling message conveyed by the item.

Another consequence of youth participation in tobacco promotions is that it enables manufacturers to compile extensive mailing lists of underage consumers. According to this survey, an estimated 1.6 million minors nationwide received promotional mail from a tobacco company. Philip Morris has reported having a mailing list of 26 million customers, ${ }^{8}$ many of whom are undoubtedly minors. Despite a stated intention to the contrary, tobacco companies have no practical way of avoiding mailing to young people when they use these lists.

Advertising through promotions enables manufactures to circumvent regulations requiring the display of health warnings. The Comprehensive Smokeless Tobacco Health Education Act of 1986 requires spit tobacco promotional items of a certain size to display a warning. Spit tobacco manufacturers have skirted these regulations, however, for example by distributing smaller items, ${ }^{9}$ although a warning may appear on the packaging. The
Federal Trade Commission (FTC) has not raised objections to these practices, nor has the FTC treated promotional items for cigarettes (as opposed to smokeless tobacco) as advertising. Thus the tobacco promotional items seen and owned by young people do not display the health warnings required of other forms of tobacco advertising.

Results from this survey indicate that young people themselves have owned more than seven million tobacco promotional items. In addition, many times this number of promotional items bearing the logo of a tobacco product but not health warnings are owned by adults and presumably seen by young people. This is evident by the finding that well over half of the survey respondents reported having a friend or relative who owned a tobacco promotional item. Promotional catalogues themselves are devoid of prominent warnings: a 1993 Camel Cash catalogue, ${ }^{10}$ for instance, displayed two inconspicuous warnings in its 16 page brochure. Such paucity of warning labels in brochures that are widely available is particularly meaningful in the light of the fact that spending on promotions now far exceeds spending by tobacco companies on newspaper and magazine advertisements, ${ }^{5}$ which are required by law to display health warnings.

Finally, the estimated 1.4 million nonsmoking youth who own tobacco promotions plus the millions of minors who browse through promotions catalogues or collect promotion coupons may represent a large pool of young people who may be at increased risk for tobacco use and subsequent nicotine addiction. A recent survey of youth in Massachusetts ${ }^{11}$ showed a dose-response relation between the degree of participation in tobacco promotion campaigns and the amount of tobacco use. This relationship is perhaps the single most important issue regarding the ownership of tobacco promotional items by young people. Millions of minors are participating in tobacco promotion campaigns, and the vast majority of new tobacco users are under the age of 18. It is not a coincidence that tobacco companies are increasing their already substantial investment in promotional items that appeal to youth. In sum, tobacco promotional items are not only reaching the American youth in large numbers; they are also almost certainly encouraging children and adolescents to use tobacco and become addicted to nicotine.

\section{RECOMMENDATIONS}

Given the widespread participation by young people in tobacco promotion campaigns, as documented in this report, we recommend the following actions: (1) the promotion of tobacco products through the distribution of specialty items bearing brand logos or symbols associated with tobacco brands should be banned; (2) if tobacco promotion campaigns are not banned, manufacturers should be required to display health warnings on all items regardless of the item's size or shape; (3) the practice of sending promotional mail and free samples of tobacco products by mail 
should be stopped; (4) federal agencies such as the FTC and the Food and Drug Administration have authorities that should be brought to bear on this problem; and (5) individuals and community groups should take action to decrease the involvement by local merchants in tobacco promotion campaigns.

This investigation was supported by grant No 18107 from the Robert Wood Johnson Foundation and by the Stanford University Medical Scholarship

\footnotetext{
1 Blum A. Cigarette cards - irony in propaganda. Tobacco Control 1995; 4: 117-8 DiFranza JR, Richards JW, Paulman PM, Wolf-Gillespie
N, Fletcher C, Jaffe RD, et al. RJR Nabisco's cartoon
camel promotes Camel cigarettes to children. $\mathcal{f} A M A$
1991; 266: 3149-53.
}

3 DiFranza JR, Tye JB. Who profits from tobacco sales to children? f $A M A$ 1990; 263: 2784-7.

4 US Federal Trade Commission. Report to Congress for 1993: pursuant to the Federal Cigarette Labeling and 1993: pursuant to the Federal Cigarette Labeling and Advertising $A$

5 Cigarette advertising and promotion in the United States, 1992. Tobacco Control 1994; 3: 286-9.

6 US Bureau of the Census. Statistical abstract of the United States: 1994 (14th ed). Washington, DC 1994.

7 Bezilla R. Teen-age attitudes and behavior concerning tobacco. Princeton, New Jersey: Gallup International Institute, September 1992.

8 Shapiro E. Cigarette makers outfit smokers in icons, eluding warning and enraging activists. Wall Street fournal, December 27, 1993.

9 Slade I. Spit tobacco makers evade US warning label requirements. Tobacco Control 1994; 3: 73-4.

10 The Official Camel Cash Catalog, vol IV. RJ Reynolds Tobacco Company, 1993.

11 Connolly GN. The master manipulator: manipulating the product, manipulating the message. Presentation at the Fifth International Conference of the Tobacco Control
Movement, Sponsored by STAT (Stop Teenage AdMovement, Sponsored by STAT (Stop Teenage Ad-
diction to Tobacco). San Jose, California, June 1995.

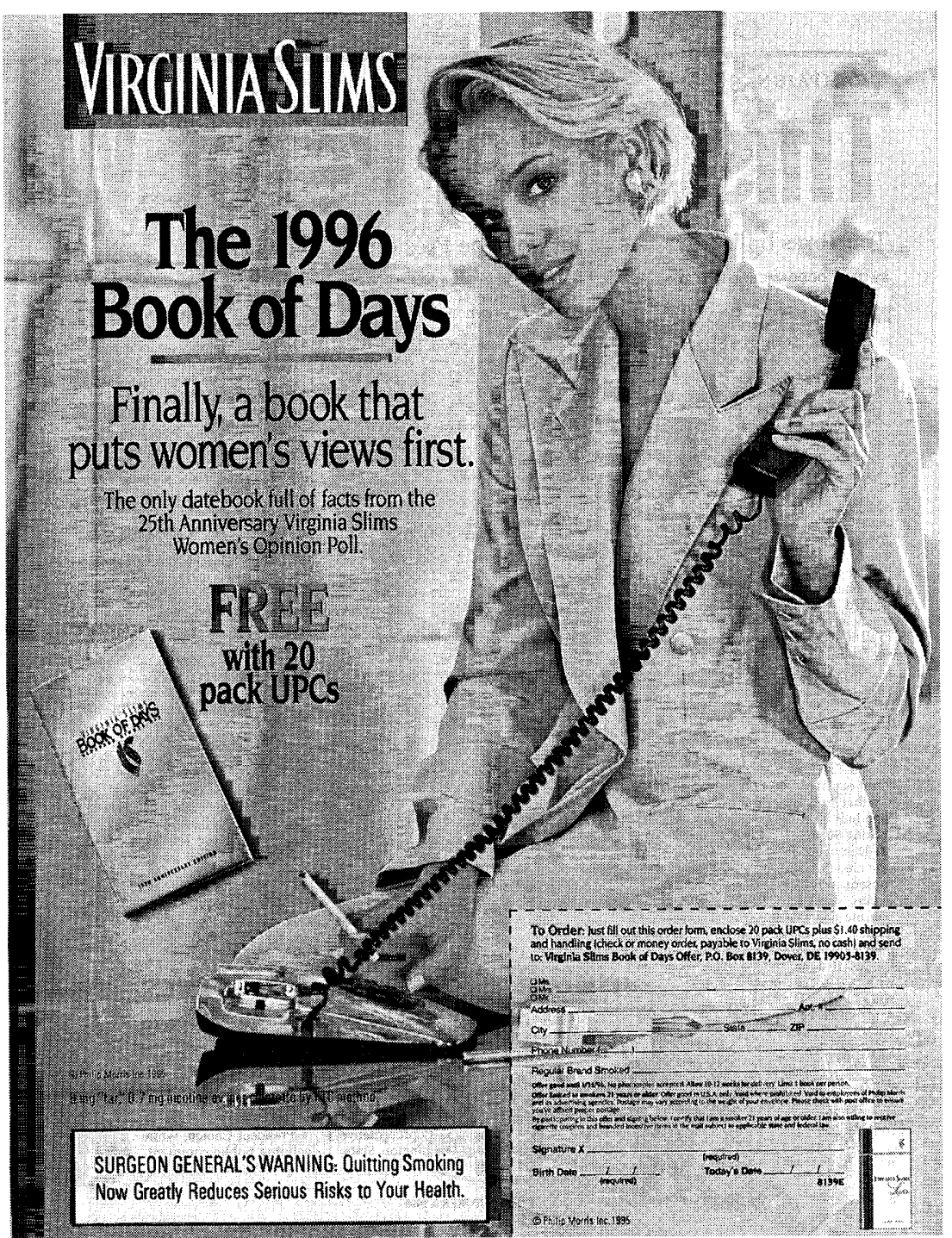

Advertisement for the Virginia Slims 1996 Book of Days, a datebook "full of facts from the 25th Anniversary Virginia Slims Women's opinion poll", free in exchange for 20 pack UPCs. 